\title{
Multi-stakeholders platforms as a process of innovation system learning: experience of sustainable and integrated exploitation of inland valleys in Benin
}

\author{
François Vihôdé DOSSOUHOUI ${ }^{1}$, Zountchégbé Yves MAGNON ${ }^{1 *}$, Christophe KINHA ${ }^{2}$, \\ Rigobert Cocou TOSSOU ${ }^{1}$ and Philippe LEBAILLY ${ }^{3}$ \\ ${ }^{1}$ Faculty of Agriculture, University of Abomey-Calavi, Benin (FSA/UAC). \\ ${ }^{2}$ Fédération des Unions de Producteurs du Benin (FUPRO - Benin). \\ ${ }^{3}$ Universite de Liège - Agro Bio Tech Gembloux - Belgique. \\ *Corresponding author; E-mail: ymagnonfr@yahoo.fr, Tel: +22997367856
}

\begin{abstract}
This research was prompted by the low used of the technologies and innovations developed by the researchers. This paper presents an experience of rice production intensification through multi-stakeholders platforms (MSP) in two provinces of Benin: Mono and Couffo. Its objective is to draw the lessons learned from this experience, especially the role and place of capacity building in the process. MSP process description and actors' perceptions analysis serve as empirical evidence to reach this objective. Innovation systems perspective is used in this article. The innovation systems concept focuses not merely on the science suppliers but on the totality and interaction of actors involved in innovation. Innovation is viewed in a social and economic sense and not purely as a discovery and invention. MSP in this project is seen as a mechanism through which the various actors in local rice value chain, with common or divergent interests, come together to learn, act and innovate in a systemic manner. Capacity building has played a key role in the process of the MSP building. Actors' perceptions are evaluated through the achievements so far and the weaknesses of the experience. Lessons learned and further challenges were described. The study suggested the use these lessons learned to promote MSP in the view to facilitate access the technologies and innovations for the clusters actors at grassroot level.
\end{abstract}

(C) 2019 International Formulae Group. All rights reserved

Keywords: Multi-stakeholders platform, innovation systems, actors, capacity building, agribusiness.

\section{INTRODUCTION}

The last two decades have witnessed renewed emphasis on the need for agricultural research and development to be holistic and integrated in its approach. Recently, the concept of innovation systems is gaining importance in agricultural research programs. Whereas before the word innovation was used loosely for everything (technology) being new, it stands now for the recognition that technology generation is not a linear process but a complex dynamic one, involving a range of actors beyond the ones who use or apply the technology for production purposes (Dantas, 2005; Spielman, 2006). Technology generation is only one element of innovation and that there are all kinds of other innovations.

This shift in perspective allows the understanding of technocratic context while capturing intricate relationships between diverse actors, processes of institutional 
learning and change, market and endogenously determined technological and institutional opportunities.

Innovation systems approach takes an action and systems perspective (Hall et al., 2001; Flood, 2002). Conventional research approach tended to embrace reductionism where by phenomena is studied in constituent parts in terms of their cause and effect relationships (Flood, 2002). Reductionist science is at the heart of the linear 'teaching' model of transfer of technology model and in general the diffusion of innovation model that has dominated science. This model is traditionally oriented towards the technology and the products rather than towards clients and interactions.

Taking on an innovation system approach means a way of working that takes into account the complex dynamics of multiple actors in a fast changing environment. As such, it implies not only a research process but requires also interactive learning processes and a search for win-win solutions through negotiation and compromises. The added valued of this collaborative approach is multidimensional: economic, social, ecological and political. Facilitation and capacity building are very important inputs in this approach.

In Benin, many experiences are ongoing with the objective to improve the effectiveness and the quality of the impacts of innovation processes in agricultural development. Various categories of actors are involved in the innovation system in Benin.

This paper presents an experience of rice production intensification through multistakeholders platforms (MSP) in two municipalities of Dogbo (Couffo) and Houéyogbé (Mono) in Benin (Figure 1). Its objective is to draw the lessons learned from this experience especially, the role and place of capacity building in the process. MSP process description and actors' perceptions analysis will serve as empirical evidence to reach this objective. To achieve this, the various reports and documents produced in the process have been screened and analyzed interviews have been held with actors involved in the experience on the ground.

\section{MATERIALS AND METHODS \\ Theoretical background}

Innovation systems' perspective is used in this article. For the World Bank 'An innovation system may be defined as comprising the organizations, enterprises and individuals that together demand and supply knowledge and technology, and the rules and mechanisms by which these different agents interact. The innovation systems concept focuses not merely on the science suppliers but on the totality and interaction of actors involved in innovation. It extends beyond the creation of knowledge to encompass the factors affecting demand for and use of new and existing knowledge in novel and useful ways. Thus, innovation is viewed in a social and economic sense and not purely as discovery and invention' (The World Bank, 2007:6-7). Thus, innovation system is not limited to the actors or groups of actors involved in the system but also the process of networking and the interactive learning among these actors. These actors may be farmers, input industries, processors, traders, researchers, extension, government officials, and/or civil society organizations.

One implication of innovation systems thinking is that the innovation capacity of a country's agricultural sector depends on the extent of shared visions, effective linkages and information flows among public and private actors; incentives for cooperation, adequate marketing, legislative, and policy environments; and well-developed human and organizational capital (Hall, 2006; Gijsbers, 2009; Klerkx et al., 2009).

\section{Methodological approach}

The study was led to the southwest of Benin in the departments of Mono and Couffo. The field experiences had been conducted from June 2009 to 2013 in the municipalities of Dogbo (Couffo) and Houéyogbé (Mono). Two multi-stakeholders had been setup, facilitated and evaluated at the end of the project. The choice of these two municipalities and villages was directed by the volume of the rice produced, the wiliness of the actors and the chance of sustainability of the experiences after the project. 
According to the theoretical approach which underlies this study, the methodological approach followed a holistic logic. The methodology is essentially qualitative. We proceeded at first to a thorough literature review and to preliminary discussions with resource persons, among which in particular researchers, agents of agricultural extension, farmer's leaders, local storekeepers, etc. This first stage allowed us to have useful orientation information on agricultural policies and rice programs and projects in Benin.

We had facilitated the process. To capitalize the experiences, we then realized focus group with these actors, constituted in homogeneous and heterogeneous groups, to understand their respective roles, their perceptions about the organization of the rice sector and their points of view on the changes which they consider necessary for the intensification of the production and the improvement of the rice sector.
Individual semi-directed interviews completed the focus group method. They took place with the actors having participated in focus group, but also widened to other actors belonging in particular to the category of the producers and the researchers. The interview guides especially concerned the actors and their roles in the sector of the production of the rice in Benin, perceptions of the actors on their respective roles, the relations between the various categories of actors, the levers of the improvement of the rice sector, the determiners and the results of the capacity building.

In total, the surveys had targeted key actors involved in the MSP functioning. The cross-checking and triangulation of the informations obtained from the different sources helped to situate each category of actor in the system formed by Multistakeholder's platforms.

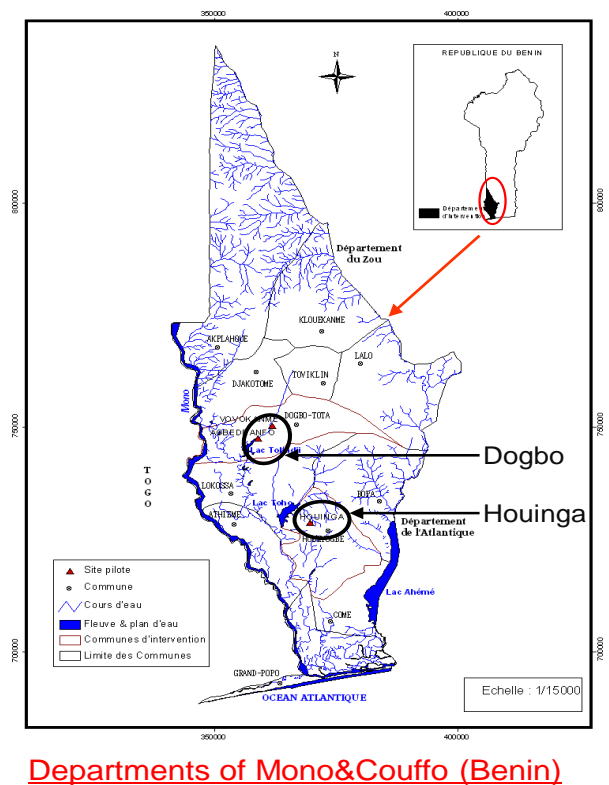
Area: $3761 \mathrm{~km}^{2}$
Population density : 238 inh./ $\mathrm{km}^{2}$
Rainfall: $950 \mathrm{~mm}$
Wet season: June-September
Major crops: rice, maize, leafy-vegetable
Artesian wells

Figure 1: Map of the region of Mono \& Couffo with the surveyed villages. 


\section{RESULTS}

\section{The process of multi-stakeholders platform building Objectives, roles and responsibilities of the MSP}

The 'Realizing Agricultural Potentials' project RAP, aimed at improving the living conditions of poor people in rural areas. In Benin, this project has been implemented by AfricaRice through two MSP. MSP in this project is seen as a mechanism through which the various actors in rice production chain, with common or divergent interests, come together to learn, act and innovate in a systemic manner. The main objectives of the MSP are:

- Strengthening the innovation capacities of lowlands rice producers through colearning processes;

- Facilitating and monitoring the various organizational and institutional mechanisms set up for the co-learning processes;

- Stimulating the co-learning processes through which the various stakeholders in rice production acquire intensification and diversification capacities;

To reach these objectives, many activities have been carried out, roles and responsibilities fulfilled. The main activities are; the choice and validation of the production sites to be considered, identification and characterization of the actors to be involved, identification of knowledge and the information systems in the sites, basic capacity building and the diagnostic study of the strength and weaknesses of the innovation approaches in lowlands rice production in the selected sites.

The roles and responsibilities assigned to the MSP are; to extend, diversify and intensify the production in the sites, promoting a sustainable agriculture which takes into account its social, economic, cultural and ecological dimensions. MSP has also the responsibility to identify in collaboration with the various researchers' groups the needs of the actors in terms of research. To fulfill these roles and responsibilities, the MSP mobilize the necessary human, material and financial resources through its members, the municipalities, the technical support institutions and the financial resources providers.

The main stakeholders involved in the MSP are the landowners, the farmers and their organizations, the herders, the fish raisers, the traders, the processors, the transportation facilitators, the researchers, the NGOs, the extension agents and the municipalities. Most of these categories of actors are members of the management committee.

\section{The MSP building process}

The MSP in the RAP project has been built through three (3) main phases which are fully integrative, iterative and interactive: the MSP setup (steps 1,2 and 3); the strategic planning, implementation \& management (steps 4, 5, 6, 7 and 8); and the monitoring, learning and adaptation (steps 9, 10, 11 and 12). These phases have been operationalized into twelve (12) steps as follows (Figure 2):

1. Exploration phase,

2. Identification of potential stakeholders,

3. MSP construction,

4. Activities planning,

5. Setting of the management committee,

6. Mobilization of the necessary resources,

7. Implementation of activities,

8. Monitoring \& evaluation (of the activities, the process and the results)

9. Partnership impact evaluation,

10. Partnership improvement,

11. Up scaling / institutionalization,

12. Internalization of the process.

Role of facilitation and capacity building in the process

The facilitation \& backstopping activities comprise the facilitation of meetings, drafting of management documents and laws, installation of the platform, and the provision of various information as needed.

The need-oriented trainings are carried out by the specialists (researchers, developers and NGOs) members of the platform and the two other capacity building activities are managed by external facilitators. 
Capacity building has played a key role in the process of MSP building in the RAP project. Three types of capacity building activities have been executed: the basic training, the need-oriented training and the facilitation \& backstopping activities.

Basic training comprises in-door sessions given to members of the management committee in order to enhance the MSP process, to facilitate communication and interaction between members and other useful knowledge. The main training sessions organized in this context are: groups \& conflict management, multi-stakeholder's activities planning, internal financial control $\&$ drafting, value chain analysis, marketing techniques, etc. Some exchange visits have been organized in order to share the experiences gained through the multistakeholder's process.

The need-oriented training are on-thefield and practical activities which are mainly technical oriented and focused on rice production techniques, scheme management, water management and the diversification and intensification techniques. These trainings are given by the researchers, NGOs and extension agents who are members of the MSP.

\section{Actors' perceptions on the MSP process and results so far}

Actors' perceptions are evaluated through the achievements so far and the weaknesses of the experience.

\section{The main achievements}

Three types of results have been identified by the actors engage in the process: capacity building, the development and strengthening of the partnership between actors, and the tangible outputs.

According to the various actors, the training sessions organized at the beginning of the process, the need-orientation training and the facilitation and backstopping activities enabled the process to move smoothly although its speed is actually low. In fact, there is a committee in the field which manages the interaction and activities of the platform correctly. Collective actions are identified and carried out by stakeholders in order to solve their common problems (access to market, cultivable land, certified seed production, and inputs etc.). A process of agribusiness starts developing.

The development and strengthening of the partnership between actors are noticed through the continuous collaboration between actors with regards to the scheme management for rice production access to market, inputs, water, roads built to facilitate circulation of people and supply in quality and quantity of seeds needed.

Some of the tangible outputs obtained through the MSP concern the construction of storage infrastructures, the access to and/or broaden of the market for rice products and inputs (seeds, fertilizers, tractors, etc.). The level of rice and vegetable production increased seriously (more than 45\%). Farmers organize themselves to produce enough certified seeds for themselves and for other producers in the area. New activities such as fish and livestock raising are carried out by the farmers.

\section{The weaknesses and constraints of the} process as perceived by the main actors

Despite all these achievements, the organizational level of the MSP and the farmers' organizations, members of the platform are still low. The management committee has not internalized the process enough. Its capacity for negotiation with external resource providers is low. There is suspicion and sabotage between the members of the MSP in such a way that the collective actions needed are not yet fully effective. Farmers think they still have difficulties to access to specific inputs and they lack equipment such as tractors and other infrastructure including drying platforms.

The initiative of MSP building in the inland valleys is facing many economic, technical and natural constraints. Low rice price at village level, increase in land costs, 
lack of processing facilities for rice and vegetables are some of the economic constraints. The main bottlenecks at technical level concern lack of water management abilities (drainage), access to water for out-ofseason production and lack of tractors and ox plough. Other constraints such as water flood and rice predator (birds and rodents) control are also noticed.

\section{Lessons learned and further challenges}

As shown by the results presented above, the MSP in the RAP project are in their early stages. Stakeholders in these platforms seemed very enthusiastic about the process. To guarantee a high level of sustainability for the initiative, the municipalities are really involved in the management of the platform. However, problems do exist and need to be solved.

Overall, the main learning points which can be derived from this experience of enhancing sustainable innovation systems in rice production through the MSP can be labeled as follows:

- It is difficult to work together with different actors that have different perspectives. A little more time is needed to make the MSP move smoothly. Many reasons support the need for more time and individual members of the MSP have difficulty to integrate the activities of the platform into their own activities, i.e., they are not always available on time. There is the multiplicity of the planned activities to solve all the problems faced by members however the situation can be corrected with time as the committee will learn by doing.

The committee has difficulties in phrasing their problems in a way that is researchable for scientists. In fact, due to the level and the variety of actors and members of the managing committee, the diagnosis carried out is not deep enough and the actions identified are not specific. These actions cannot be tackled by research at the short run. They need more time and sometimes skills that are not available. This means that the initial capacity building activities are not enough to guarantee an effective and efficient functioning of the MSP. Continuous facilitation and capacity strengthening are needed. Researchers also need to improve their capacities to identify relevant research questions from the global diagnosis carried out by MSP. This is a recurrent problem since the same bottlenecks have been identified with extension services in Benin with the so-called 'Approche Participative Niveau Village'.

- The articulation between the MSP on one hand and researchers and developers on the other hand needs to be improved. The MSP are not fully considered by them as useful actors and so still behave as in the top-down approach. This means that researchers and developers' capacities in using MSP as partners in the research and extension processes need to be strengthened.

- $\quad$ Emphasis needs to be put on how to promote collaborative work. Skills in group dynamics or groups management seem too narrow to induce the required behavior and know-how.

Articulation of the MSP with the local and regional administrative body is useful for sustainability. The involvement of the mayor of the municipalities in the MSP facilitates the interaction with other relevant actors which are not members of the platform, especially with the regional and national administration and donors. 


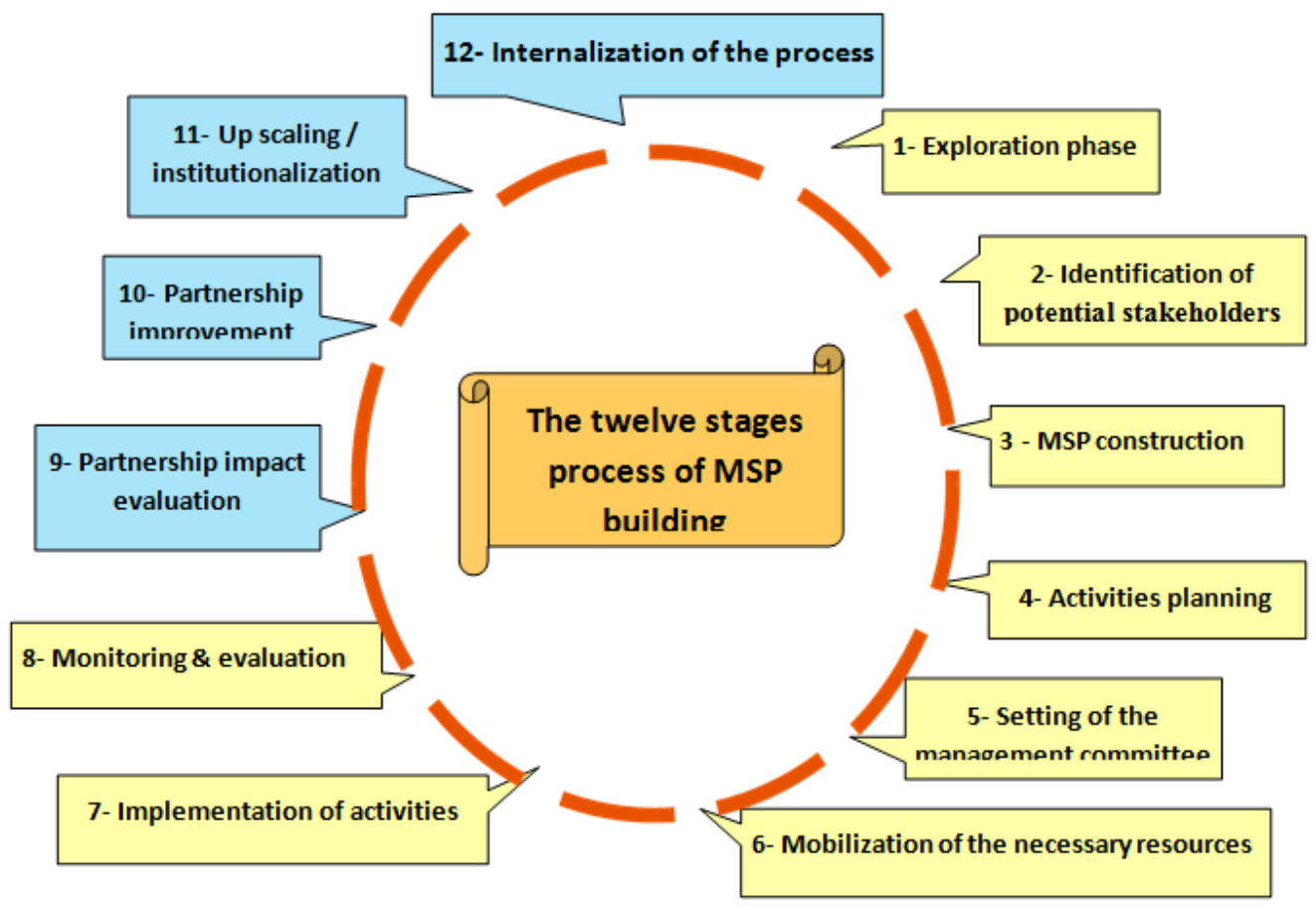

Figure 2: Phases of the MSP.

\section{DISCUSSION}

The establishment of an innovation platform is an interactive learning process between actors at the local level. It takes a little time to get off to a good start despite the enthusiasm it generates among the actors at the start. Our discussion points will focus on the main lessons learned and their operationally for the multiplication of the experience of PSM.

It was noted that it is difficult to work with different actors with different perspectives. But every significant human accomplishment is the result of coordinated group behavior-people working together to achieve a common goal. Of course, that reality doesn't change the fact that for lots of people, teamwork is like pulling teeth. Psychologists know there's a universal human need to belong to groups, but they also know that people aren't always predisposed to working well with each other. Individual interests often sabotage team spirit. People's competitive instincts end up finding targets in fellow team members rather than rival teams. In fact, even when we want to collaborate, the wrong expertise, incompatible values, or an unusual style could make just about anybody a poor match for a given team. Talented leaders are good at picking the right people for the right task, and inspiring them to set aside their selfish agendas to focus on the group's goals. Indeed, the ability to build high-performing teams is basically the essence of leadership.

The committee has difficulties in phrasing their problems in a way that is researchable for scientists. The MSP objective is to bring the researchers to work on the relevant issues facing by the local rice value chain actors. "Communication challenges can arise, however, when attempting to address specific research questions in these collaborations. In particular, inconsistencies can exist between scientists and community members in the use and interpretation of words and other language features. Additional challenges arise from differing perceptions of the investigative process. There may be divergent perceptions about how research questions should and can be answered, and in 
expectations about requirements of research institutions and research timelines" Amy Colquhoun et al. (2013). From these differences, misunderstandings can occur about how the results will ultimately impact the community. These communication issues are particularly challenging when scientists and community members are from different ethnic and linguistic backgrounds that may widen the gap between ways of talking and thinking about science, further complicating the interactions and exchanges that are essential for effective joint research efforts.

For MSP development, emphasis needs to be put on how to promote collaborative work. All the actors are in equal situation. The top-down approach should be banned. For sustainability, interaction with local administrations and other relevant actors should be recommended. "A good facilitator is crucial, especially at the start, but we should not underestimate the role of platform members. It is therefore essential to recruit actors with representative and issue-related expertise and operational capacities, coupled with communicative qualities, openmindedness, and dynamism van Paassen, A., L and al. (2013).

\section{Conclusion}

In conclusion, to make MSP a useful tool for development, it is necessary to develop the skills of all the stakeholders involved, and this includes researchers and farmers in the case of the RAP project. Initial facilitation and trainings may concern not only farmers but researchers and developers as well. These trainings have to be reinforced according to emerging needs and may be based on the collective experiences gained through the MSP.

\section{COMPETING INTERESTS}

The authors declare that they have no competing interests.

\section{AUTHORS' CONTRIBUTIONS}

FVD was involved in study design, data collection and analysis, and writing of this paper; ZYM was involved in the study design, data analysis and writing of this paper; CK was involved in study design and data collection; RCT was involved in study design and correction of this paper; PL was involved in study design and correction of this paper.

\section{ACKNOWLEDGEMENTS}

The authors would like to thank all MSP collaborators in Mono / Couffo, and AfricaR/INRAB researchers involved in these MSP experiences of RAP project. We are grateful to Sylvain EFIO for his technical assistance and to two anonymous reviewers for their helpful comments.

\section{REFERENCES}

Colquhoun A, Geary J, Goodman KJ. 2013. Challenges in conducting communitydriven research created by differing ways of talking and thinking about science: a researcher's perspective. Int $J$ Circumpolar Health, 72: DOI: $10.3402 /$ ijch.v72i0.21232

Dantas E. 2005. The 'system of innovation' approach, and its relevance to developing countries. SciDev.net'. https://www.scidev.net/global/policybrief/the-system-of-innovationapproach-and-its-relevanc.html

Flood RL. 2002. The Relationship of 'systems thinking' to Action Research. In Handbook of Action Research: Participative inquiry and Practice, Reason P, Bradbury H (eds). Sage: London.

Gijsbers G. 2009. Agricultural innovation in Asia: Drivers, paradigms and performance. $\mathrm{PhD}$ thesis, Erasmus Research Institute of Management, Rotterdam, The Netherlands. $347 \mathrm{p}$

Hagmann J. 1999. Learning together for change. Facilitating innovation in natural resource management through learning process approaches in rural livelihoods in Zimbabwe. Kommunikation und Beratung, No. 29. Weikersheim, Germany: Margraf Verlag.

Hall A, Bockett G, Taylor S, Sivamahan MVK, Clark N. 2001. Why research partnerships really matter: Innovation 
theory, institutional arrangements and implications for developing new technology for the poor. World Development, 29(5): 783-798.

Hall A. 2006. Public-private partnerships in an agricultural system of innovation: Concepts and challenges. International Journal of Technology Management and Sustainability Development, 5(1): 3-20.

Klerkx L, Hall A, Leeuwis C. 2009. Strengthening agricultural innovation capacity: Are innovation brokers the answer? International Journal of Agricultural Resources, Governance and Ecology, 8(5/6): 409-438.

Sellamna NE. 1999. Relativism in agriculture research and development: Is participation a postmodern concept? Working paper 119. Overseas Development Institute (ODI). London
Spielman DJ. 2006. A Critique of Innovation Systems Perspectives on Agricultural Research in Developing Countries. Innovation Strategy Today, 2(1): 41-54.

van Paassen A, Klerkx L, Adu-Acheampong R, Adjei-Nsiah S, Ouologuem B, Zannou E, Vissoh P, Soumano L, Dembele F, Traore M. 2013. Choice-making in facilitation of agricultural innovation platforms in different contexts in West Africa: experiences from Benin, Ghana and Mali. Knowledge Management for Development Journal, 9(3): 79-94. http://journal.km4dev.org/

World Bank. 2007. Enhancing agricultural innovation: How to go beyond the strengthening of research systems. World Bank: Washington, D.C. 